doi:10.1185/030079906X115757

7. Permsuwan U, Thavorn K, Dilokthornsakul $\mathbf{P}_{\text {, }}$ Saokaew S, Chaiyakunapruk N. Costeffectiveness of insulin detemir versus insulin glargine for Thai type 2 diabetes from a payer's perspective. J Med Econ. 2017;20(9):991-999. doi:10.1080/13696998.2017.1347792
8. Guillermin A-L, Samyshkin $Y$, Wright $D$, Nguyen T, Villeneuve J. Modeling the lifetime costs of insulin glargine and insulin detemir in type 1 and type 2 diabetes patients in Canada: a metaanalysis and a cost-minimization analysis. J Med Econ. 2011;14(2):207-216. doi:10.3111/ 13696998.2011 .561390

\title{
ĐÁNH GIÁ BIẾN CHỨNG TRONG LOAI BỎ CÁC TỔN THƯƠNG VÚ BIRADS 2 VÀ 3 BẰNG SINH THIẾT VÚ Có HỖ TRỢ HÚT CHÂN KHÔNG TẠI BỆNH VIỆN BACH MAI
}

\section{TÓM TẮT}

Mục tiêu: Đánh giá bước đầu biến chứng trong xử lý các tổn thưỡng vú lành tính bằng phương pháp sinh thiết vú có hố trợ hút chân không tại trung tâm Điện quang, bệnh viện Bạch Mai. Đối tượng và phương pháp nghiên cứu: nghiên cứu tiến cứu can thiệp không đối chứng trên các bệnh nhân nữ có tổn thương vú lành tính được loại bỏ hoàn toàn bằng kim sinh thiết có hỗ trợ hút chân không dưới hướng dẫn siêu âm từ tháng 1 năm 2018 đến tháng 12 năm 2019 tại Trung tâm điện quang bệnh viện Bạch Mai. Kết quả: 32 bệnh nhẩn nữ được loại bỏ 44 tổn thương vú lành tính (đã được chọc tể bào trước đó). Tuổi trung bình 36,5; hay gặp ở nhóm 20-30 tuổi (33,6\%). Kết quả giải phẫu bệnh, u xơ tuyến vú hay gặp nhất với tỷ lê $62,2 \%$, thứ hai là biến đổi xơ nang chiếm $17,8 \%$. Các biến chứng hay gặp sau khi sinh thiết là đau và máu tụ tại chố. 77,3\% bệnh nhân sau điều trị không phải dùng thuốc giảm đau. Kích thước trung bình máu tụ sau 3 tháng là 3,2 mm. Kết luận: Phương pháp sinh thiết vú có sự hố trợ hút chân không là phương pháp an toàn để loại bỏ hờn toàn tổn thương vú lành tính, cho kết quả giải phẫu bệnh đáng tin cây trong khi chỉ gặp biến chứng nhẹ như đau, bâm tím và tụ máu nhỏ.

Tư khóa: Sinh thiết vú có hỗ trợ hút chân không, tổn thương vú lành tính

\section{SUMMARY}

EVALUATING THE COMPLICATION IN THE REMOVAL OF BREAST BENIGN LESIONS BY VACUUM-ASSISTED BIOPSY IN BACHMAI HOSPITAL

A experimental research was performed in radiology center of Bach Mai hospital to evaluate the complication in the removal of breast benign lesions by vacuumassisted biopsy. Subjects and methods: There is a prospective intervention study in 32 female patients

1 Trung tâm Điện quang, Bệnh viện Bạch Mai

Chịu trách nhiệm chính: Trần Anh Tuấn

Email: bs.trananhtuan@yahoo.com.vn

Ngày nhận bài: 4.3.2021

Ngày phản biên khoa học: 23.4.2021

Ngày duyệt bài: 7.5.2021

\section{Trần Anh Tuấn ${ }^{1}$, Nguyễn Phương Anh ${ }^{1}$}

with 44 breast benign lesions with needle aspiration vacuum-assisted biopsy under ultrasound guidance from January 2018 to December 2018. Results: The mean age is 36.5 years old. The $20-30$ years old group is most common (30.6\%). The most common abnormality pathology is breast fibroadenoma (62.2\%). Fibrocystic breast disease accounts for $17.8 \%$ of all lesions, which is second highest rate. The main complications after biopsy are pain and hematoma in tissu. 77,3\% of patients after treatment don't have to take Paracetamol. The average size of hematoma after 3 month is $3.2 \mathrm{~mm}$. Conclusion: Vacuum-assisted breast biopsy is a safe method for removal benign breast lesions completely. It provides the reliable histological result while the complication just includes painess, bruises and small hematoma.

Keywords: Vacuum-assisted biopsy, breast benign lesions.

\section{I. ĐĂT VẤN ĐỀ}

Bệnh vú là môt trong những bệnh lý phổ biến ở phụ nữ. Theo GLOBOCAN 2018, tỷ lệ mới mắc u vú ác tính là 2,09 triệu ca một năm [1], [2]. Trong hai thập kỷ qua, các kỹ thuật mới phát triển nhằm tìm tổn thương ung thư vú đồng thời cũng làm tăng tỷ lệ phát hiện tổn thương vú lành tính [3], [4]. Tổn thương vú phân loại theo BIRADS chủ yếu thuộc BIRADS 2 và 3 , tổn thương vú dù phân loại BIRADS 2 (lành tính) và BIRADS 3 (98\% lành tính) nhưng cũng gây khó chịu, đau, giảm chất lượng cuộc sống cho bệnh nhân [5]. Do vậy, người ta tìm kiếm phướng pháp điêu trị lấy bỏ hoàn toàn tổn thương, ngày càng hướng đến can thiệp tổn thiểu, hiệu quả, có tính thẩm mỹ cao. Phương phát sinh thiết vú có sự hỗ trợ hút chân không (VABB) đã ra đời và đáp ứng được các yêu câu trên. Phương pháp này lần đâu tiên được giới thiệu bởi Burbank và cộng sự vào năm 1995 trên thế giới, được sử dụng sinh thiết vú dưới siêu âm năm 1998 [6]. Tính đến nay đã có rất nhiều nghiên cứu đánh giá hiệu quả của phương pháp này trong loại bỏ tổn thương vú và khẳng định phương pháp đem 
lại hiệu quả, an toàn, thẩm mỹ cao và được bệnh nhân chấp nhận, ưa chuộng [7], [8], [9]. Tại Việt Nam, phương pháp này đã được áp dụng từ năm 2017 tại bệnh viện ung bướu thành phố Hồ Chí Minh và tiếp theo là Trung tâm Điện quang - bệnh viện Bạch Mai(12/2017) với mục đích chẩn đoán cũ̃ng như điều trị bệnh vú, bước đầu cho thấy hiệu quả tốt. Tuy nhiên vấn cần đánh giá các hạn chế của phương pháp, do vậy chúng tôi thực hiện nghiên cứu này để lượng giá các biến chứng có thể gặp của phương pháp hút chân không các khối u lành tính tuyến vú.

\section{II. ĐỐI TƯợNG VÀ PHƯƠNG PHÁP NGHIÊN CỨU Tiêu chuẩn lựa chọn:}

- Tổn thương trên siêu âm thuộc nhóm BIRADS 2,3 theo ACR năm 2013.

- Có hồ sơ bệnh án đầy đủ thông tin

- Có chỉ định sinh thiết vú có sự hỗ trợ hút chân không

- Bệnh nhân đồng ý tham gia nghiên cứu.

* Chỉ định sinh thiết vú có hố trợ hút chân không trong nghiên cứu của chúng tôi là chỉ định điêu trị, các trường hợp sau:

1. Những tổn thương vú có triệu chứng không nghi ngờ là ung thư biểu mô với mục đích loại bỏ hoàn toàn dưới hướng dẫn phương pháp chẩn đoán hình ảnh.

2. Các tổn thương nội ống hoặc trong nang, đặc biệt các trường hợp có triệu chứng tiết dịch núm vú, gây đau cho bệnh nhân.

Phương pháp nghiên cứu. Nghiên cứu tiến cứu, can thiệp không đối chứng

- Cỡ mấu: Thuận tiện, thức tế thực hiện trên 32 bệnh nhân với 44 tổn thương vú

- Địa điểm, thời gian nghiên cứu: Trung tâm điện quang - bệnh viện Bạch Mai từ tháng 01 năm 2018 đến tháng 12 năm 2019.

Quy trình thực hiện sinh thiết vú có sự hỗ trợ hút chân không . Kỹ thuật sinh thiết vú có sự hỗ trợ hút chân không được thực hiện bằng máy siểu âm LOGIQ E9 với đầu dò Linear $15 \mathrm{MHz}$, sử dụng kim sinh thiết vú cõ̃ kim $8 \mathrm{G}$ hoăc 10G. Việc lựa chọn cõ kim phụ thuộc vào kích thước và hình dạng tổn thương.

Trước khi thực hiện sinh thiết vú bệnh nhân được xác định tổn thương mục tiêu (là tổn thương cần loại bỏ). Gây tê vùng sinh thiết vú gồm gây tê da và dưới da $0,5 \mathrm{ml}$ Lidocain $2 \%$; sau đó dùng kim $18 \mathrm{G}$ gây tê xung quanh tổn thương bằng Lidocain $2 \%$ pha loãng $1: 5$, đồng thời tách tổn thương với cơ ngực lớn, da, núm vú. Tiến hành đưa kim sinh thiết vú tiếp cận bên dưới tổn thương. Cắt và hút liên tục lấy mẫu bệnh phẩm cho đến khi lấy hết hoàn toàn tổn thương và được quan sát thời gian thực dưới siêu âm. Rút kim, băng ép và cầm máu. Bệnh nhân ra viện sau 2 giờ, sử dụng thuốc kháng sinh đường uống, thuốc cầm máu và chống viêm. Băng ép cố định duy trì 24 giờ.

Tổn thương tồn dư hay biến chứng sẽ được theo dõi bằng lâm sàng và siêu âm sau sinh thiết 1 tuần, 1 tháng, 3 tháng và 6 tháng. Các biến chứng quan trọng gồm: đau, vết bầm tím da và máu tụ. Trong đó máu tụ được xác định bằng siêu âm và triệu chứng đau được chia làm các mức độ:

- Không đau

- Đau nhẹ, không phải sử dụng thuốc giảm đau

- Đau vừa, cần dùng thuốc giảm đau thông thường (Paracetamol), không phải nhập viện.

- Đau nặng, dùng thuốc giảm đau thông thường không đỡ, phải nhập viện để điều trị giảm đau

Thu thập số liệu, thổng tin bệnh nhân theo một mẫu bệnh án nghiên cứu thống nhất, dựa trên hồ sơ bệnh án và số liệu thu nhận trong quá trình thực hiện sinh thiết vú có sự hỗ trợ hút vú chân không. Xử lý số liệu bằng phần mềm SPSS 20.0.

- Đạo đức nghiên cứu. Phương pháp loại bỏ tổn thương vú bằng sinh thiết có hỗ trợ hút chân không đã được thông qua bởi hội đồng khoa học bệnh viện Bach Mai.

\section{KẾT QUẢ NGHIÊN CỨU}

3.1 Đặc điểm chung: Chúng tôi đã thực hiện sinh thiết tổn thương vú lành tính bằng phương pháp hút chân không trên 32 bệnh nhân với 44 tôn thương (12 bệnh nhân thực hiện ở cả 2 vú). Tuổi trung bình là $36,5 \pm 10,6$. Bệnh nhân ít tuổi nhất 21 , nhiều tuổi nhất là 62 . Nhóm 2030 tuổi có tỷ lệ cao nhất (33,6\%).

Bảng 1: Các triệu chứng lâm sàng

\begin{tabular}{|c|c|c|}
\hline $\begin{array}{c}\text { Triệu chứng (theo tốn } \\
\text { thương) }\end{array}$ & $\mathbf{n}$ & Tỷ lệ\% \\
\hline Đau & 38 & 84,4 \\
\hline Đau liên quan kinh nguyệt & 22 & 48,9 \\
\hline Sờ thấy khối & 35 & 77,8 \\
\hline
\end{tabular}

Nhận xét: Triệu chứng đau và sờ thấy khối là hai triểu chứng hay gặp, lânn lượt 84,4 và $77,8 \%$.

Bảng 2. Đặc điểm tổn thương trên siêu âm 2D (n=44)

\begin{tabular}{|c|c|c|c|c|}
\hline Đặc điểm & $\begin{array}{c}\text { Giá trị } \\
\text { trung } \\
\text { binh }\end{array}$ & $\begin{array}{c}\text { Đô lệ̂̉ } \\
\text { chuẩn }\end{array}$ & Min & Max \\
\hline $\begin{array}{c}\text { Kích thước } \\
\text { (mm) }\end{array}$ & 13,2 & 6,7 & 05 & 34 \\
\hline Cách da (mm) & 6,4 & 3,3 & 2,0 & 17,0 \\
\hline $\begin{array}{c}\text { Cách cơ ngực } \\
\text { lớn (mm) }\end{array}$ & 3,6 & 3,1 & 0 & 18,0 \\
\hline
\end{tabular}




\begin{tabular}{|c|c|c|c|c|}
\hline $\begin{array}{c}\text { Cách núm vú } \\
(\mathrm{mm})\end{array}$ & 19,3 & 10,9 & 0 & 50 \\
\hline
\end{tabular}

Nhận xét: Kích thước trung bình của tốn thương 13,2 $\pm 6,7 \mathrm{~mm}$, phần lớn khối u nông, cách bề mặt da $6,4 \mathrm{~mm}$

3.2 Kết quả giải phẫu bệnh:

Bảng 3: Kết quả giải phấu bệnh

\begin{tabular}{|c|c|c|}
\hline & $\begin{array}{c}\text { Số tốn } \\
\text { thương }\end{array}$ & $\begin{array}{c}\text { Tỷ lề } \\
(\%)\end{array}$ \\
\hline U xơ tuyến vú & 28 & 63,6 \\
\hline Biến đối xơ nang & 07 & 15,9 \\
\hline U nhú nội ống & 02 & 04,6 \\
\hline Viêm xơ tuyến vú & 02 & 04,6 \\
\hline App xe viêm mủ & 01 & 02,3 \\
\hline Bệnh tuyến xơ hóa & 01 & 02,3 \\
\hline $\begin{array}{c}\text { Quá sản đơn thuần/ } \\
\text { viêm xơ tuyến vú }\end{array}$ & 01 & 02,3 \\
\hline $\begin{array}{c}\text { Quá sản ống/ u xớ } \\
\text { tuyến vú }\end{array}$ & 01 & 02,3 \\
\hline Tốn thương nội ống & 01 & 02,3 \\
\hline
\end{tabular}

Nhân xét: Tỷ lệ BN được hút chân không có tổn thương u xơ lành tính là hay gặp nhất

\section{$(63,6 \%)$}

3.3 Biến chứng sau sinh thiết

Bảng 4: Biến chứng bầm tím, đau sau sinh thiêt

\begin{tabular}{|c|c|c|c|c|}
\hline & $\begin{array}{l}\text { Số tốn } \\
\text { thương }\end{array}$ & $\begin{array}{l}\text { Tỷ lệ } \\
\text { \% }\end{array}$ & $\mathbf{p}$ \\
\hline \multicolumn{2}{|c|}{ Tồn dư tổn thương } & 0 & 0 & \\
\hline \multirow{2}{*}{$\begin{array}{l}\text { Bầm } \\
\text { tím da }\end{array}$} & Không & 40 & 90,1 & \multirow{2}{*}{0,001} \\
\hline & Có & 04 & 9,1 & \\
\hline \multirow{4}{*}{ Đau } & Không & 7 & 15,9 & \multirow{4}{*}{0,02} \\
\hline & Nhe & 27 & 61,4 & \\
\hline & Vừa & 10 & 22,7 & \\
\hline & Nặng & 0 & 0 & \\
\hline
\end{tabular}

Nhân xét: $100 \%$ các tốn thương được lấy bỏ hoàn toàn (đánh giá lại trên siêu âm). Tỷ lệ không để lại vết bầm tím trên da chiếm 90,1\%. Sau sinh thiết chủ yếu đau nhe chiếm tỳ lệ 61,4\%; đau vừa chiếm 22,7\%; Không có bênh nhân nào đau mức độ nặng. 77,3\% bệnh nhân không phải sử dụng thuốc giảm đau sau sinh thiết hút tổn thương. Không gặp biến chứng nhiễm trùng, thủng hay hoại tử da.

Bảng 5: Biến chứng máu tụ và theo dôi máu tụ

\begin{tabular}{|c|c|c|c|c|c|}
\hline $\begin{array}{c}\text { Kích thước máu } \\
\text { tụ }(\mathbf{m m})\end{array}$ & $\begin{array}{c}\text { Ngay sau } \\
\text { thư thuật }\end{array}$ & Sau 1 tuân & $\begin{array}{c}\text { Saú 1 } \\
\text { tháng }\end{array}$ & $\begin{array}{c}\text { Sau 3 } \\
\text { tháng }\end{array}$ & Sau 6 tháng \\
\hline Số ca theo dõi & 44 & 44 & 44 & 43 & 43 \\
\hline Số ca bỏ theo dõi & 0 & 0 & 0 & 01 & 01 \\
\hline Giá trị trung bình & 7,5 & 8,6 & 6,3 & 3,6 & 2,0 \\
\hline Độ lệch chuấn & 5,9 & 5,0 & 3,3 & 2,0 & 1,6 \\
\hline Min & 1,6 & 3,0 & 0,0 & 0,0 & 0,0 \\
\hline Max & 22 & 22 & 15 & 09 & 05 \\
\hline
\end{tabular}

(Mỗi bên vú được tính là 1 trường hợp độc lập được theo dỗi)

Nhân xét: Máu tụ giảm dần theo thời gian, thời điểm sau 6 tháng hầu như máu tụ hết khi kích thước máu tụ chỉ còn trung bình khoảng $2 \mathrm{~mm}$

3.3 Tương quan giữa kích thước u và máu tu:

Bảng 6: Môi tương quan giữa kích thước u và lượng máu tụ( $(n=44)$

\begin{tabular}{|c|c|c|c|}
\hline & $\begin{array}{c}\text { Số BN } \\
\text { (theo số } \\
\text { lượng vú) }\end{array}$ & $\begin{array}{c}\text { Lượng máu } \\
\text { tụ sau thú } \\
\text { thuật }\end{array}$ & p \\
\hline $\begin{array}{c}\text { Khối } \\
>25 \mathrm{~mm}\end{array}$ & 02 & $\begin{array}{c}18,5 \pm \\
2,1 \mathrm{~mm}\end{array}$ & \multirow{2}{*}{0,036} \\
\hline $\begin{array}{c}\text { Khối } \\
\leq 25 \mathrm{~mm}\end{array}$ & 42 & $\begin{array}{c}7,0 \pm \\
5,6 \mathrm{~mm}\end{array}$ & \\
\hline
\end{tabular}

(có 32 bệnh nhân trong đó có 12 bệnh nhân được làm 2 bên)

Nhận xét: Khối u càng lớn nguy cơ chảy máu sau hút chân không càng lớn. Có mối liên quan tỷ lệ thuân giữa kích thước khối u và máu tu sau sinh thiểt, có ý nghĩa thống kê.

Bảng 7: Môi liên quan giữa tỷ lể biến chứng và cỡ kim thực hiện hút vú chân

không (n=44)
\begin{tabular}{|c|c|c|c|c|}
\hline Cỡ kim & $\mathbf{8 G}$ & $\mathbf{1 0 G}$ & Tổng & $\mathbf{p}$ \\
\hline Biến chứng & 14 & 20 & 34 & \\
\hline Không & 07 & 03 & 10 & \multirow{2}{*}{0.11} \\
\hline Cón & $\mathbf{2 1}$ & $\mathbf{2 3}$ & $\mathbf{4 4}$ & \\
\hline Tống & 21 &
\end{tabular}

Nhận xét: Không có sự khác biệt về biến chứng giữa kim $8 \mathrm{G}$ và $10 \mathrm{G}$.

\section{BÀN LUÂN}

Nghiên cứu của chúng tôi bước đầu đánh giá trên 32 bệnh nhân với 44 tổn thương. Tuổi trung bình của nhóm bệnh nhân 36,5 tuổi. Nhóm 20 30 tuổi chiếm tỷ lệ cao nhất, kết quả này phù hợp với các nghiên cứu của Oluwole [5].

Tỷ lệ sờ thấy khối trên lâm sàng chiếm $77,8 \%$, cao hơn so với nghiên cứu của tác giả Park và cộng sự [6]. Nguyên nhân do phần lớn tổn thương được bệnh nhân phát hiện trước khi vào viên. Kích thước trung bình của tổn thương trên siểu âm là $14,6 \mathrm{~mm}$, có giá trị cao hơn so với nghiên cứu của tác giả Park [6]. 
Kết quả giải phẫu bệnh, $u$ xơ tuyến vú (fibroadenoma) hay gặp nhất với tỷ lệ $62,2 \%$, thứ hai là biến đổi xớ nang chiếm $17,8 \%$, kết quả này tương tự với các nghiên cứu khác trên thế giới [9].

Tỷ lẹ̣ bệnh nhân đau sau sinh thiết mức độ vừa (đau cần dùng thuốc giảm đau) chiếm $22,7 \%$. Nghiên cứu của tác giả Li $\mathrm{S}$ và cộng sự trên 1578 bệnh nhân cũng cho kết quả tương tự [9]. Có 15,9\% bệnh nhân không đau, 77,3\% không phải sử dụng thuốc giảm đau sau sinh thiết vú có hỗ trợ hút chân không. 90,1\% bênh nhân không để lại vết bầm tím trên da sau thủ thuật.

Ngay sau sinh thiết, tụ máu có độ dày trung bình 7,4 $\pm 5,9 \mathrm{~mm}$. Tổn thương có khối máu tụ sau sinh thiết nhỏ nhất là $1,6 \mathrm{~mm}$; lớn nhất là $22,0 \mathrm{~mm}$. Với nhóm sinh thiết bằng kim $8 \mathrm{G}$, kích thước máu tụ 9,4 $\pm 1,5 \mathrm{~mm}$. Với nhóm sinh thiết bằng kim 10G, kích thước máu tụ 5,2 $\pm 0,7 \mathrm{~mm}$. Kích thước trung bình máu tụ sau một tuần lớn hơn so với ngay sau thực hiện thủ thuật. Các đợt theo dõi sau 1 tháng, 3 tháng và 6 tháng, kích thước máu tụ giảm dần. Có mối liên quan tỷ lệ thuân giữa kích thước khối u và máu tụ sau sinh thiết, có ý nghĩa thống kê $(p=0,001)$. Có một thực tế là khi thực hiện kim 8G thì thời gian thực hiện thủ thuật kéo dài hơn với số lần chọc và hút nhiều hơn, do đó nhận thấy khối máu tụ sau thủ thuật cũng lớn hơn so với kim 10G.

Tỷ lệ có biến chứng nhóm dùng kim 8G 07/21 trường hợp tương đương $33,3 \%$. Tỷ lệ này ở nhóm dùng kim 10G 03/23 trường hợp tương đương 13,3\%. Như vậy ta thấy lợi ích của việc dùng kim 10G là tốt hớn so với kim 8G.

Kích thước khối máu tụ thay đổi tùy thuộc vào khối u trước làm thủ thuật lớn hay nhỏ, mức độ đàn hồi của mô vú, lực hút chân không trong lúc làm thủ thuật và lực ép tổn thương ngay sau làm. Mô vú ở phụ nữ thay đổi từ dạng mô tuyến đến mô mõ. Phu nữ trẻ, chưa nuôi con bú thường dạng mô tuyến, có độ đàn hồi cao hơn, kích thước máu tụ sau thủ thuật thường ít hơn.

Nhóm tổn thương kích thước dưới $25 \mathrm{~mm}$ có lượng máu tụ 7,0 \pm 5,6mm nhỏ hơn nhóm có kích thước lớn hơn $25 \mathrm{~mm}$ có lượng máu tụ 18,5 $\pm 2,1 \mathrm{~mm}$, sự khác biệt này có ý nghĩa thổng kê với $\mathrm{p}=0,036$. Trước đây, với tổn thương hơn $25 \mathrm{~mm}$ phương pháp này thường không lấy được hết tổn thương, hiệu quả không cao, nhưng hiện nay với sự phát triển của khoa học công nghệ, kỹ thuật sinh thiết vú có hỗ trợ hút chân không được thực hiện tốt hơn, có thể cắt bỏ hoàn toàn khối $25-30 \mathrm{~mm}$ Trong nghiên cứu này của chúng tôi, có tổn thương lớn nhất đường kính $34 \mathrm{~mm}$ được cắt bỏ hoàn toàn trong một lần thực hiện thủ thuật.

Thủ thuật hút chân không không ghi nhận trường hợp nào bị biến chứng nhiễm trùng, không có biến chứng thủng da, hoại tử da. Như vậy đây là phương pháp khá an toàn.

Tất cả các tổn thương mục tiêu đều được loai bỏ hoàn toàn bằng phương pháp sinh thiết có hỗ trợ hút chân không,với thời gian ngắn, ít biến chứng, bệnh nhân hồi phục nhanh và ra viện trong ngày. Kết quả này tương tự như các nghiên cứu khác trên thế giới, cho thấy đây là phương pháp an toàn, hiệu quả, rút ngắn thời gian và chi phí nằm viện cho người bệnh.

\section{KẾT LUẬN}

Phương pháp sinh thiết vú có sự hỗ trợ hút chân không là phương pháp an toàn, ít biến chứng trong khi loại bỏ hoàn toàn tổn thương vú lành tính. Các biến chứng có thể gặp là đau $(22,7 \%$ cần dung thuốc giảm đau), bầm tím da, máu tụ tại chỗ (sau 3 tháng máu tụ còn trung bình $3,6 \mathrm{~mm}$ ) và hầu như không gặp các biến chứng nặng như nhiễm trùng, hoại tử da và tuyến vú.

\section{TÀI LIỆU THAM KHẢO}

1. Figueroa J.D., Pfeiffer R.M., Brinton L.A. và cô̂ng sứ. (2016). Standardized measures of lobular involution and subsequent breast cancer risk among women with benign breast disease: a nested case-control study. Breast Cancer Res Treat, 159(1), 163-172.

2. Kotepui M., Piwkham D., Chupeerach C. và cộng sứ. (2014). Epidemiology and histopathology of benign breast diseases and breast cancer in southern Thailand. Eur J Gynaecol Oncol, 35(6), 670-675.

3. Vacuum-Assisted Biopsy (brand names, Mammotome or MIBB) | Biopsy | Imaginis - The Women's Health \& Wellness Resource Network. $<$ http://www.imaginis.com/biopsy/vacuumassisted-biopsy-brand-names-mammotome-ormibb-1>, accessed: 24/06/2018.

4. Luo H., Chen X., Tu G. và cộng sự. (2011). Therapeutic application of ultrasound-guided 8gauge Mammotome system in presumed benign breast lesions. Breast J, 17(5), 490-497.

5. Oluwole S.F. và Freeman H.P. (1979), Analysis of benign breast lesions in blacks. Am J Surg, 137(6), 786-789.

6. Park H.-L., Kwak J.-Y., Lee S.-H. và cộng sự. (2005). Excision of Benign Breast Disease by Ultrasound-Guided Vacuum Assisted Biopsy Device (Mammotome). Ann Surg Treat Res, 68(2), 96-101.

7. Fine R.E., Israel P.Z., Walker L.C. và công sứ. (2001). A prospective study of the removal rate of imaged breast lesions by an 11-gauge vacuumassisted biopsy probe system. Am J Surg, 182(4), 335-340.

8. Clinical application of mammotome minimally invasive biopsy system for excision of 
560 benign breast lumps--Lingnan Modern Clinics in Surger $2007 \quad<$ http://en.cnki.com. cn/Article_en/CJFDTOTAL-LNWK

200705013.htm>, accessed: 04/06/2018.
9. Li S., Wu J., Chen K. và cộng sự. (2013). Clinical outcomes of 1,578 Chinese patients with breast benign diseases after ultrasound-guided vacuum-assisted excision: recurrence and the risk factors. Am J Surg, 205(1), 39-44.

\title{
ĐÁNH GIÁ KẾT QUẢ SAU THÁO DẦU SILICON NộI NHÃN TRÊN MẮT ĐÃ PHẪU THUÂTT VIÊM MỦ NộI NHÃN DO VẾT THƯƠ'NG XUYÊN NHÃN CẦU
}

\author{
Phan Thị Thu Hương*, Thẩm Trương Khánh Vân*, \\ Nguyễn Thị Thu Hiền*, Nguyễn Thị Thu Yên*
}

\section{TÓM TẮT}

Mục tiêu: Đánh giá kết quả sau tháo dầu silicon nôi nhã̃n trên mắt đã phẫu thuât viêm mủ nội nhãn do vết thương xuyên nhãn cầu. Đối tượng và phương pháp nghiên cứu: Nghiên cứu mô tả, tiến cứu không đối chứng trên 30 mắt của 30 bệnh nhân đã được tháo dâu silicon sau mổ cắt dich kính điều trị viêm mủ nội nhãn do vết thương xuyên nhãn câu có bơm dâu silicon nội nhãn, tại khoa Chấn thương mắt bệnh viện Mắt Trung Ương. Kết quả: Về chức năng: thị lực cải thiện là 73,33\%, có sự khác biệt rõ ràng giữa thị lực saư phấu thuật và thị lực lúc vào viện; nhãn áp sau phẫu thuật: phần lớn ở mức bình thường $90 \%$, có $3,33 \%$ nhãn áp cao và $6,67 \%$ nhãn áp thấp do biến chứng bong võng mạc. Về mặt giải phâuu: 36,67\% các mắt sạch dâuu buông dịch kính và $56,67 \%$ là còn bóng dầu nhỏ; võng mạc áp chiếm $90 \%$ số mắt. Kết luận: Tháo dâu silicon nội nhãn đem lại hiệu quả cải thiên rõ rệt về mặt chức năng và giải phẫu cho các mắt đã được điều trị viêm mủ nôi nhãn do vết thương xuyên nhẳn cầu đã được cắt dịch kính mủ kèm ân độn nội nhãn bằng dầu silicon nhãn

Từ khóa: tháo dầu silicon nội nhãn, viêm mủ nội

\section{SUMMARY \\ OUTCOMES AFTER SILICONE OIL \\ REMOVAL IN ENDOPHTHALMITIS DUE OCULAR PENETRATING INJURIES}

Objectives: To evaluate the outcomes after Silicone oil removal in endophthalmitis due to ocular penetrating injuries. Subjects and methods: Descriptive, prospective, uncontrolled study on 30 eyes of 30 patients who had silicone oil removed after vitrectomy to treat endophthalmitis due to transocular trauma with oil pump. Intraocular silicone, at the Department of Eye Trauma, Central Eye Hospital. Result: In terms of function: improved visual acuity is $73.33 \%$, there is a clear difference between visual acuity after surgery and visual acuity at hospital

*Bệnh viện Mắt Trung ương

Chiu trách nhiẹm chính: Phan Thị Thu Hương

Email: dr.huongphan@gmail.com

Ngày nhận bài: 10.3.2021

Ngày phản biện khoa học: 29.4.2021

Ngày duyệt bài: 11.5.2021 admission; IOP after surgery: most of them are in $90 \%$ normal range, there are $3.33 \%$ high IOP and $6.67 \%$ low IOP due to retinal detachment complications. Anatomically: $36.67 \%$ of the eyes were clear of vitreous oil and $56.67 \%$ had small oil balls; Pressure retina accounts for $90 \%$ of the eyes. Conclusion: Removal of intraocular silicone oil brought a significant improvement in function and anatomy for the eyes treated with endophthalmitis due to the trans-ocular wound that had been removed with purulent vitreous and intraocular pressure. silicone oil label.

Key Words: Silicone oil removal, silicone oil, endophthalmitis

\section{I. ĐẶT VẤN ĐỀ}

Phẫu thuật cắt dịch kính (CDK) kèm bơm dầu silicon nôi nhãn là phương pháp hữu ích được áp dụng để điều trị viêm mủ nội nhãn (VMNN) do vết thương xuyên nhãn cầu (VTXNC) nhằm loại bỏ và hạn chế sư phát triển của tác nhân gây bênh và độc tố, đồng thời giúp võng mac không bị bong, giúp thuốc kháng sinh - chống viêm khuyếch tán tốt hơn, chống hạ nhãn áp. Tưy nhiên, dầu silicon không thể lưu lại vĩnh viễn trong mắt. Sau một thời gian (khoảng từ 2 tháng) dầu silicon có thể nhuyễn hóa gây nên các biến chứng cho các mô nội nhãn như võng mac, thể thủy tinh, giác mac.... Do đó, sau khi đã đạt được hiệu quả điều trị, dầu silicon cần được lấy khỏi mắt sớm. Vậy sau khi tháo dầu silicon nội nhãn, liệu tình trạng giải phẫu cũng như chức năng thi giác của mắt có được cải thiên? Chúng tôi đã tiến hành nghiên cứu "Đánh giá kêt quả sau tháo dầu silicon nội nhãn trên mắt đã phẫu thuật viêm mủ nội nhãn do vết thương xuyên nhã̃n cầu" nhằm mục tiêu: Đánh giá kết quả sau tháo dầu silicon nội nhãn trên mắt đã phẫu thuật viêm mủ nội nhãn do vêt thương xuyên nhãn cầu.

\section{II. ĐỐI TƯỢNG VÀ PHƯƠNG PHÁP NGHIÊN CỨU \\ 2.1. Đối tượng nghiên cứu \\ 2.1.1. Đối tượng nghiên cứu: Nghiên cứu}

